1 Supporting Information Online for

2

3 Modeling Organic Aerosols in a Megacity: Comparison of Simple and Complex

4 Representations of the Volatility Basis Set Approach

5 1,* Manish Shrivastava, ${ }^{1}$ Jerome Fast, ${ }^{1}$ Richard Easter, ${ }^{1}$ William I. Gustafson Jr., ${ }^{1}$ Rahul A.

6 Zaveri, ${ }^{2}$ Jose L. Jimenez, ${ }^{3}$ Pablo Saide, and ${ }^{4}$ Alma Hodzic

$7{ }^{1}$ Atmospheric Sciences \& Global Change Division, Pacific Northwest National Laboratory,

8 Richland, WA 99352

$9 \quad{ }^{2}$ University of Colorado, Boulder, CO

$10{ }^{3}$ Center for Global and Regional Environmental Research, University of Iowa, Iowa City, Iowa, 11 USA

$12{ }^{4}$ National Center for Atmospheric Research, Boulder, CO

21 *Corresponding author: ManishKumar.Shrivastava@pnl.gov 
The main text describes implementation of three WRF-Chem modeling cases evaluating

24 OA formation against highly time resolved AMS PMF measurements using the MILAGRO 2006

25 case study in Mexico City. The supporting information presented here complements the main

26 text providing further details including figures and discussions comparing the 9-species and 2-

27 species VBS approaches at other ground sites and along aircraft flight transects.

\section{S1.0. Evaluation of $\mathrm{OA}$ at remote sites}

In the main text we evaluated OA predictions at two ground sites: an urban T0 site and

30 suburban T1 site at the edge of the city. It is also instructive to evaluate OA variations at sites

31 located farther from the city. In this section we look at two remote sites: T2 and Altzomoni. The

32 T2 site was located $35 \mathrm{~km}$ to the north north-east of T1 at Rancho la Bisnaga, at an altitude of

$332542 \mathrm{~m}$. There are few significant anthropogenic emission sources between T1 and T2, and

34 somewhat higher concentrations of OC and EC were found at T2 during periods of southwesterly

35 winds (Doran, 2007). The mountain site of Altzomoni was located $60 \mathrm{~km}$ south-east of Mexico

36 City at an altitude of 4010m (Baumgardner et al., 2009). The Altzomoni site is generally above

37 regional mixed layer from late evening until late morning. The T2 and Altzomoni sites are

38 indicated in Figure 1a.

39 Using a thermal-optical OC/EC analyzer, Doran et al. (2007) reported organic carbon

40 (OC) concentrations at the T2 site, which are converted to OA using an OM/OC ratio of 1.4.

41 Another way would be to derive OC from WRF-Chem predictions for direct comparison to

42 measured OC. However, both methods have uncertainties associated with OM/OC ratio, as OC

43 emissions in the inventory are derived assuming fixed OM/OC of 1.25 for fossil and 1.57 for

44 biomass emissions. In addition, traditional biogenic and anthropogenic SOA in WRF-Chem need 
45 to be converted to OC. In this work, we choose the former method of comparing OA instead of

46 OC, acknowledging the inherent uncertainties with both approaches. Figure S1a and S1b

47 compare 24-day average diurnal variations of OA and SOA from the 3 modeling cases. AMS

48 OOA is not available for comparison to model predictions in Figure S1b. Figure S1a shows that

49 Case 2 and Case 3 reasonably predict concentrations of OA. Also no strong diurnal variation in

50 absolute OA concentrations at T2 site is apparent. A comparison of Figure S1a and S1b shows

51 that model predictions indicate SOA to be dominant component of OA at this site throughout the 52 day.

53 Figure S1c and S1d show 24-day average diurnal variations of OA and SOA respectively

54 at the high altitude Altzomoni site. The top of the mixed layer reaches the altitude of Altzomoni

55 at about 11-12 LT and remains above this altitude until after 20 LT. All modeling scenarios

56 reproduce magnitude and diurnal variation of measured OA concentrations (using AMS) as

57 shown in Figure S1c. As expected, both OA and SOA concentrations increase at this site after

$58 \quad 11 \mathrm{LT}$ as the top of the mixed layer reaches the altitude of $4 \mathrm{~km}$. As with the T2 site, most of the

59 simulated OA at the Altzomoni site is comprised of SOA.

60 S1.1. Evaluation of OA components aloft

61 AMS measurements aloft are available from G-1 (Kleinman et al., 2008) and C-130

62 (DeCarlo et al., 2008) aircraft flight transects. The two aircrafts made several transects on

63 different days flying above the center of Mexico City and downwind. This data is valuable for

64 studying time evolution and growth of organic aerosols due to gas-particle partitioning and

65 photochemical aging of organics in the atmosphere. In this study, high time-resolution AMS

66 PMF data (10-s data) from eight G-1 flights including 6a, 7a, 15a, 18a, 19a, 20a, 20b, 22a (a and

67 b refer to morning and afternoon flights), and two C-130 flights (on March 10 and 29) are used 
68 to evaluate simulated OA. The G-1 aircraft flew over Mexico City and up to $50 \mathrm{~km}$ northeast of

69 the city, whereas the C-130 also flew farther downwind over the Gulf of Mexico.

Figure S2 compares WRF-Chem output for Case 2 vs. PMF results from the AMS aboard

71 the G-1 and C-130 flights. Results are shown as scatter plots of mass concentrations vs. CO

72 mixing ratios. Higher $\mathrm{CO}$ mixing ratios $(\geq 500 \mathrm{ppbv})$ are generally associated with the city center

73 or within fire plumes, while lower $\mathrm{CO}$ mixing ratios represent instances when aircrafts were

74 flying farther downwind. Figure S2a and S2c show that HOA is significantly under-predicted

75 aloft over Mexico City and immediately downwind of city. HOA predictions improve at farther

76 downwind locations (CO mixing ratios lower than $250 \mathrm{ppb}$ ). SOA predictions in Figures $\mathrm{S} 2 \mathrm{~b}$ and

77 S2d show the reverse trend as compared to HOA. SOA predictions are much better over the city

78 and immediate downwind locations, but SOA is over-predicted as compared to AMS OOA at

79 more remote downwind locations. The two branches appearing in HOA and SOA scatter plots

80 for Case 2 predictions in Figure S2 are interesting. In Figure S2b, the first branch showing high

81 SOA at low $\mathrm{CO}$ concentrations (below $250 \mathrm{ppb} \mathrm{CO}$ ) comes mainly from higher anthropogenic

82 A-SI-SOA contributions for five G-1 flight paths. Higher BB-SI-SOA contributed to higher SOA

83 at downwind locations for the remaining three G-1 flight paths on $15^{\text {th }}, 18^{\text {th }}$ and $19^{\text {th }}$ March at

84 downwind locations as compared to within the city. In Figure S2d, some of the highest SOA

85 predictions at downwind locations are caused by high A-SI-SOA on $10^{\text {th }}$ March 2006 . High BB-

86 SI-SOA also contributes to downwind SOA on both $10^{\text {th }}$ and $29^{\text {th }}$ March 2006. Significant

87 contributions of A-SI-SOA downwind are also consistent with the high downwind HOA branch

88 from model predictions appearing in both Figures S2a and S2c. In comparison to model

89 predictions, PMF HOA shows more scatter (Figures S2a and S2c). The model has difficulty

90 representing this scatter, thus highlighting significant uncertainties in representation of spatial 
91 and temporal variation of emission sources in the 2006 MCMA inventory. This inconsistency

92 related to uncertainties in emissions inventory has also been shown in previous work by Fast et

93 al. (2009).

$94 \quad$ S2.0. Non-fossil carbon fraction $\left(f_{\mathrm{NF}}\right)$

$95{ }^{14} \mathrm{C}$ measurements provide insights into relative contributions of fossil and modern

96 carbon. These measurements provide another metric to evaluate predictions of source-oriented

97 models such as WRF-Chem. Substantial amounts of non-fossil carbon as a fraction of total OC

$98\left(f_{\mathrm{NF}}\right)$ are observed in both urban locations such as Mexico City and in remote environments of

99 the Northern Hemisphere throughout the year (Hodzic A., 2010). High values of $f_{\mathrm{NF}}$ observed in

100 urban environments such as Mexico City during low biomass burning events points towards

101 importance of representing non-fossil sources in emission inventories (Hodzic A., 2010). These

102 sources include biogenic SOA, primary biological particles (PBAP) and urban sources of non-

103 fossil carbon such as food cooking, municipal trash burning, biofuel use, etc.

104 In this work $f_{\mathrm{NF}}$ is calculated using following assumptions: $20 \%$ of urban carbon (both

105 primary and secondary) is non-fossil, $15 \%$ of biogenic SOA is PBAP consistent with results

106 from Hodzic et al. (2010), and both BBOA and SOA from biomass burning are non-fossil carbon

107 sources. $f_{\mathrm{NF}}$ is not sensitive to dilution effects resulting from variation in boundary layer height

108 as it is a ratio. Also $f_{\mathrm{NF}}$ does not depend on amount of oxygen added in the S/IVOC oxidation 109 parameterization, as it is based on carbon fraction.

110 The non-fossil carbon fraction $\left(f_{\mathrm{NF}}\right)$ is found to range from $0.37-0.67$ at $\mathrm{T} 0$ and $0.50-0.86$

111 at T1, with a substantial disagreement between two datasets collected by two different groups,

112 which remains unresolved (Hodzic A., 2010). Figure S3 shows the average diurnal variation of $113 f_{\mathrm{NF}}$ at the T0 and T1 sites respectively using Case 2 indicated by solid lines. The figure shows $f_{\mathrm{NF}}$ 
114 values ranging from $0.26-0.40$ and $0.34-0.43$ at the T0 and $\mathrm{T} 1$ sites respectively. Consistent with

115 estimations by Hodzic et al. (2010), $f_{\mathrm{NF}}$ values at the T1 site are predicted to be higher by about

1160.1 as compared to the T0 site. Also, Figure S3 indicates that $f_{\mathrm{NF}}$ values at both sites increases

117 during the day after $08 \mathrm{LT}$ with a peak value at $18 \mathrm{LT}$.

118 We note that B-V-SOA is too low in our model compared to previous studies as

119 discussed earlier. So, $f_{\mathrm{NF}}$ is recalculated in our model by increasing B-V-SOA by a factor of 5 at 120 the T0 and T1 sites as indicated by dashed lines in Figure S3, keeping concentrations of all other

121 OA components unaltered. Increasing B-V-SOA causes an increase in $f_{\mathrm{NF}}$ by 0.04 and 0.05 at the $122 \mathrm{~T} 0$ and T1 sites respectively on an average.

123 It is also important to note that WRF-Chem predicts $f_{\mathrm{NF}}$ (average $\sim 0.36$ at T0 when 124 biogenic SOA is corrected as above) which are slightly lower than the Aiken et al. (2010) $f_{\mathrm{NF}}$ 125 dataset (average of 0.44), consistent with the results of Hodzic et al. (2010). Since WRF-Chem 126 has missing biomass emissions especially during early morning which strongly affect the surface 127 average concentrations (Aiken et al., 2010), increasing amount of biomass burning emissions 128 would help to increase predicted values of $f_{\mathrm{NF}}$ bringing them into agreement to measurements, 129 consistent with the conclusions of Hodzic et al. (2010). However a separate dataset of $f_{\mathrm{NF}}$ from 130 Marley et al. (2009) reports $f_{\mathrm{NF}}$ which is larger by about 0.15 compared to the Aiken et al. (2010) 131 data, and the unexplained disagreement between these datasets limits our ability to make strong 132 conclusions based on these comparisons. In addition, accurate quantification of OA and S/IVOC 133 emissions and their non-fossil carbon fraction for anthropogenic trash burning observed within 134 and around Mexico City, as well as for other urban emissions such as food cooking and biofuel 135 use is also essential to better constrain model predictions of $f_{\mathrm{NF}}$.

136 S3.0. WRF-Chem vs. CHIMERE 
Even though CHIMERE and WRF-Chem have differences in treatments of meteorology,

138 chemistry, emissions, and coupling of meteorology with chemistry (offline versus online) they

139 are widely used by different groups and it is instructive to compare OA predictions between the

140 two models. WRF-Chem uses SAPRC-99 gas phase chemistry, whereas CHIMERE uses the

141 MELCHIOR chemical mechanism. Details of the SOA formation mechanism in CHIMERE are

142 discussed by Hodzic et al. (2009) and Hodzic et al. (2010). Since SI-SOA formation is primarily

143 controlled by $\mathrm{OH}$ concentrations, inter-comparison of $\mathrm{OH}$ concentrations simulated by

144 CHIMERE and WRF-Chem was done at the T0 site in Mexico City. Both models showed similar

145 diurnal variations for $\mathrm{OH}$, however, $\mathrm{CHIMERE}$ predicts higher average $\mathrm{OH}$ concentration as 146 compared to WRF-Chem.

147 Also, in CHIMERE, dry deposition of all gaseous semi-volatile species is calculated 148 similar to $\mathrm{NO}_{2}$ (effective Henry's law constant of $0.01 \mathrm{M}$ atm ${ }^{-1}$ ), however, in WRF-Chem dry 149 deposition is calculated using an effective Henry's law constant of $2700 \mathrm{M} \mathrm{atm}^{-1}$. Hence dry 150 deposition velocities of semi-volatile organic vapors in WRF-Chem are expected to be higher 151 than CHIMERE. However, dry deposition velocities do not directly scale with effective Henry's 152 law constant due to other factors as aerodynamic resistance, surface resistance, stomatal 153 resistance and effect of reactivity on mesophyllic resistance (Bessagnet et al., 2010). Bessagnet 154 et al. (2010) found that omitting dry deposition of semivolatile species may overestimate SOA 155 concentrations by as much as $50 \%$ especially during nighttime when relative humidity is high. 156 Quantifying effects of dry deposition on SOA concentrations is a subject for further study.

157 Figure S4 and S5 compare total OA, HOA, SOA and BBOA predictions at the T0 and T1 158 sites respectively from CHIMERE (using the ROB approach) and WRF-Chem (Case 2). 159 Temporally averaged simulated values from both the models are also indicated on each figure. 
160 The CHIMERE simulations of Hodzic et al. (2010) used an older POA emissions inventory for

161 Mexico City, while the current WRF-Chem predictions are from a recently revised inventory for

162 Mexico City for 2006, with an additional doubling of the default anthropogenic S/IVOC

163 emissions (Case 2 Cases) used for comparison. Older POA emissions used by Hodzic et al.

164 (2010) were greater than revised 2006 inventory used in this work by almost a factor of 2 at the

165 T0 site, so Case 2 predictions of HOA are similar to Hodzic et al. (2010). At the T0 site, the 166 average predictions of total OA, HOA, SOA and BBOA are very similar in both models. This is

167 encouraging as it implies that simulated OA components by the two models within Mexico City

168 are of similar order. Differences in temporal variations between WRF-Chem and CHIMERE are

169 also due to different treatments of meteorology. WRF-Chem using online meteorology as

170 discussed earlier which is more useful for simulating event periods, while CHIMERE uses 171 offline meteorology through MM5.

172 At the T1 site, shown in Figure S5a, WRF-Chem predicts on average 25\% higher total 173 OA as compared to CHIMERE. Also, on an average WRF-Chem predicts lower HOA (10\% 174 lower) and higher SOA (50\% higher) as compared to the CHIMERE model as shown in Figure $175 \mathrm{~S} 5 \mathrm{~b}$ and S5c respectively. The S/IVOC emissions have had more time for multi-generational 176 photochemistry leading to higher $\mathrm{SOA} / \Delta \mathrm{CO}$ ratios at the $\mathrm{T} 1$ site as compared to $\mathrm{T} 0$ site as 177 discussed earlier. Differences in HOA are related to differences in emissions and spatial 178 resolution of the model at the T1 site. As WRF-Chem assumes a minimum non-volatile fraction 179 of $22 \%$ of SVOC emissions for anthropogenic emissions as compared to CHIMERE where the 180 minimum non-volatile fraction is 9\% (based on ROB approach), if emissions were same, WRF181 Chem would predict higher HOA as compared to CHIMERE. In contrast, lower HOA 182 predictions from WRF-Chem indicate significant differences in emissions, transport and 
183 deposition between the two models. BBOA predictions are of the same order between 184 CHIMERE and WRF-Chem as shown in Figure S5d.

Figure S6 compares various SOA components between the two models at T1 site. Similar 186 amounts of traditional A-V-SOA are predicted by both WRF-Chem and CHIMERE as shown in 187 Figure S6a. CHIMERE predicts 5 times higher B-V-SOA as compared to WRF-Chem shown in 188 Figure S6b as discussed earlier. Figure S6c and S6d show that WRF-Chem predicts twice as 189 much A-SI-SOA and 50\% higher BB-SI-SOA compared to CHIMERE, on average, with most of 190 the higher predictions occurring after March $24^{\text {th }}$. Differences in meteorological treatments 191 between the two models are partly responsible for differences in predicted OA. Higher SI-SOA 192 predictions from WRF-Chem are also partially caused due to the addition of $15 \%$ oxygen mass 193 per generation of oxidation as compared to 7.5\% added oxygen assumed by CHIMERE model. 194 In addition, CHIMERE included treatment of precipitation and wet deposition (Hodzic et al., 195 2010), which would have greatest impact after March 24, but the amount of aerosols removed by 196 wet deposition in CHIMERE was not quantified in that study. In contrast, wet deposition is 197 excluded in WRF-Chem in the present study, as Fast et al. (2009) found that effects of wet 198 deposition removal during that period was relatively small. 


\section{S4.0. References}

Aiken, A. C., de Foy, B., Wiedinmyer, C., DeCarlo, P. F., Ulbrich, I. M., Wehrli, M. N., Szidat, S., Prevot, A. S. H., Noda, J., Wacker, L., Volkamer, R., Fortner, E., Wang, J., Laskin, A., Shutthanandan, V., Zheng, J., Zhang, R., Paredes-Miranda, G., Arnott, W. P., Molina, L. T., Sosa, G., Querol, X., and Jimenez, J. L.: Mexico city aerosol analysis during MILAGRO using high resolution aerosol mass spectrometry at the urban supersite (T0) - Part 2: Analysis of the biomass burning contribution and the non-fossil carbon fraction, Atmos. Chem. Phys., 10, 53155341, 10.5194/acp-10-5315-2010, 2010.

Baumgardner, D., Grutter, M., Allan, J., Ochoa, C., Rappenglueck, B., Russell, L. M., and Arnott, P.: Physical and chemical properties of the regional mixed layer of Mexico's Megapolis, Atmos. Chem. Phys., 9, 5711-5727, 2009.

Bessagnet, B., Seigneur, C., and Menut, L.: Impact of dry deposition of semi-volatile organic compounds on secondary organic aerosols, Atmos. Environ., 44, 1781-1787, 10.1016/j.atmosenv.2010.01.027, 2010.

DeCarlo, P. F., Dunlea, E. J., Kimmel, J. R., Aiken, A. C., Sueper, D., Crounse, J., Wennberg, P. O., Emmons, L., Shinozuka, Y., Clarke, A., Zhou, J., Tomlinson, J., Collins, D. R., Knapp, D., Weinheimer, A. J., Montzka, D. D., Campos, T., and Jimenez, J. L.: Fast airborne aerosol size and chemistry measurements above Mexico City and Central Mexico during the MILAGRO campaign, Atmos. Chem. Phys., 8, 4027-4048, 2008.

Doran, C.: "The T1-T2 study: evolution of aerosol properties downwind of Mexico City (vol 7, pg 1585, 2007), Atmos. Chem. Phys., 7, 2197-2198, 2007.

Fast, J., Aiken, A. C., Allan, J., Alexander, L., Campos, T., Canagaratna, M. R., Chapman, E., DeCarlo, P. F., de Foy, B., Gaffney, J., de Gouw, J., Doran, J. C., Emmons, L., Hodzic, A., Herndon, S. C., Huey, G., Jayne, J. T., Jimenez, J. L., Kleinman, L., Kuster, W., Marley, N., Russell, L., Ochoa, C., Onasch, T. B., Pekour, M., Song, C., Ulbrich, I. M., Warneke, C., WelshBon, D., Wiedinmyer, C., Worsnop, D. R., Yu, X. Y., and Zaveri, R.: Evaluating simulated primary anthropogenic and biomass burning organic aerosols during MILAGRO: implications for assessing treatments of secondary organic aerosols, Atmos. Chem. Phys., 9, 6191-6215, 2009.

Hodzic, A., Jimenez, J. L., Madronich, S., Aiken, A. C., Bessagnet, B., Curci, G., Fast, J., Lamarque, J. F., Onasch, T. B., Roux, G., Schauer, J. J., Stone, E. A., and Ulbrich, I. M.: Modeling organic aerosols during MILAGRO: importance of biogenic secondary organic aerosols, Atmos. Chem. Phys., 9, 6949-6981, 2009.

Hodzic, A., Jimenez, J. L., Madronich, S., Canagaratna, M. R., DeCarlo, P. F., Kleinman, L., and Fast, J.: Modeling organic aerosols in a megacity: potential contribution of semi-volatile and intermediate volatility primary organic compounds to secondary organic aerosol formation, Atmos. Chem. Phys., 10, 5491-5514, 10.5194/acp-10-5491-2010, 2010.

Hodzic A., J. J. L., Prevot A.S.H., Szidat S., Fast J.D., Madronich S.: Can 3-D models explain the observed fractions of fossil and non-fossil carbon in and near Mexico City?, Atmospheric Chemistry and Physics Discussions, 10, 14513-14556, 2010.

Kleinman, L. I., Springston, S. R., Daum, P. H., Lee, Y. N., Nunnermacker, L. J., Senum, G. I., Wang, J., Weinstein-Lloyd, J., Alexander, M. L., Hubbe, J., Ortega, J., Canagaratna, M. R., and Jayne, J.: The time evolution of aerosol composition over the Mexico City plateau, Atmos. Chem. Phys., 8, 1559-1575, 2008. 
Kroll, J. H., Ng, N. L., Murphy, S. M., Flagan, R. C., and Seinfeld, J. H.: Secondary organic 251 aerosol formation from isoprene photooxidation, Environ. Sci. Technol., 40, 1869-1877, $25210.1021 / \mathrm{es} 0524301,2006$.

253 Marley, N. A., Gaffney, J. S., Tackett, M., Sturchio, N. C., Heraty, L., Martinez, N., Hardy, K.

254 D., Marchany-Rivera, A., Guilderson, T., MacMillan, A., and Steelman, K.: The impact of 255 biogenic carbon sources on aerosol absorption in Mexico City, Atmos. Chem. Phys., 9, 1537$2561549,2009$.

257 Ng, N. L., Chhabra, P. S., Chan, A. W. H., Surratt, J. D., Kroll, J. H., Kwan, A. J., McCabe, D. 258 C., Wennberg, P. O., Sorooshian, A., Murphy, S. M., Dalleska, N. F., Flagan, R. C., and 259 Seinfeld, J. H.: Effect of NOx level on secondary organic aerosol (SOA) formation from the 260 photooxidation of terpenes, Atmos. Chem. Phys., 7, 5159-5174, 2007a.

261 Ng, N. L., Kroll, J. H., Chan, A. W. H., Chhabra, P. S., Flagan, R. C., and Seinfeld, J. H.: 262 Secondary organic aerosol formation from m-xylene, toluene, and benzene, Atmos. Chem. Phys., 263 7, 3909-3922, $2007 \mathrm{~b}$.

264 Tsimpidi, A. P., Karydis, V. A., Zavala, M., Lei, W., Molina, L., Ulbrich, I. M., Jimenez, J. L., 265 and Pandis, S. N.: Evaluation of the volatility basis-set approach for the simulation of organic 266 aerosol formation in the Mexico City metropolitan area, Atmos. Chem. Phys., 10, 525-546, 2010. 
273

274 Table S1. SOA mass yields using a 4-product VBS with $C^{*}$ of 1, 10, 100 and $1000 \mu \mathrm{g} \mathrm{m}^{-3}$ for $V$ $275 S O A$ precursors

\begin{tabular}{|c|c|c|c|c|c|c|c|c|}
\hline \multirow{3}{*}{$\begin{array}{l}\text { V-SOA } \\
\text { precursors }\end{array}$} & \multicolumn{4}{|c|}{ Aerosol Yield } & \multicolumn{3}{|c|}{ Aerosol Yield } & \multirow[b]{3}{*}{1000} \\
\hline & \multicolumn{4}{|c|}{ High NOx Parameterization } & \multicolumn{3}{|c|}{ Low NOx parameterization } & \\
\hline & 1 & 10 & 100 & 1000 & 1 & 10 & 100 & \\
\hline ALK4 & $\mathrm{N} / \mathrm{A}$ & 0.038 & $\mathrm{~N} / \mathrm{A}$ & $\mathrm{N} / \mathrm{A}$ & N/A & 0.075 & $\mathrm{~N} / \mathrm{A}$ & N/A \\
\hline ALK5 & $\mathrm{N} / \mathrm{A}$ & 0.15 & $\mathrm{~N} / \mathrm{A}$ & $\mathrm{N} / \mathrm{A}$ & $\mathrm{N} / \mathrm{A}$ & 0.3 & $\mathrm{~N} / \mathrm{A}$ & $\mathrm{N} / \mathrm{A}$ \\
\hline OLE1 & 0.001 & 0.005 & 0.038 & 0.15 & 0.005 & 0.009 & 0.06 & 0.225 \\
\hline OLE2 & 0.003 & 0.026 & 0.083 & 0.27 & 0.023 & 0.044 & 0.129 & 0.375 \\
\hline ARO1 & 0.01 & 0.24 & 0.45 & 0.7 & 0.01 & 0.24 & 0.7 & 0.7 \\
\hline ARO2 & 0.01 & 0.24 & 0.45 & 0.7 & 0.01 & 0.24 & 0.7 & 0.7 \\
\hline ISOP & 0.001 & 0.023 & 0.015 & 0 & 0.009 & 0.03 & 0.015 & 0 \\
\hline TERP & 0.012 & 0.122 & 0.201 & 0.5 & 0.107 & 0.092 & 0.359 & 0.6 \\
\hline SESQ & 0.075 & 0.15 & 0.75 & 0.9 & 0.075 & 0.15 & 0.75 & 0.9 \\
\hline
\end{tabular}


285 Table S2. V-SOA 1-product mass yields

\begin{tabular}{|l|l|l|l|}
\hline V-SOA precursors & $\begin{array}{l}\text { Aerosol Yield } \\
\text { High } \mathrm{NO}_{\mathrm{x}}\left(1 \mu \mathrm{g} \mathrm{m}^{-3}\right)\end{array}$ & $\begin{array}{l}\text { Aerosol Yield } \\
\text { Low } \mathrm{NO}_{\mathrm{x}}\left(1 \mu \mathrm{g} \mathrm{m}^{-3}\right)\end{array}$ & Reference \\
\hline ARO1 & 0.08 & 0.304 & (Ng et al., 2007b) \\
\hline ARO2 & 0.035 & 0.367 & (Ng et al., 2007b) \\
\hline TERP & 0.066 & 0.379 & (Ng et al., 2007a) \\
\hline SESQ & 0.847 & 0.417 & (Ng et al., 2007a) \\
\hline ISOPRENE & 0.038 & 0.01 & (Kroll et al., 2006) \\
\hline ALK4 & 0.038 & 0.075 & (Tsimpidi et al., 2010) \\
\hline ALK5 & 0.15 & 0.3 & (Tsimpidi et al., 2010) \\
\hline OLE1 & 0.001 & 0.005 & (Tsimpidi et al., 2010) \\
\hline OLE2 & 0.003 & 0.023 & \\
\hline
\end{tabular}



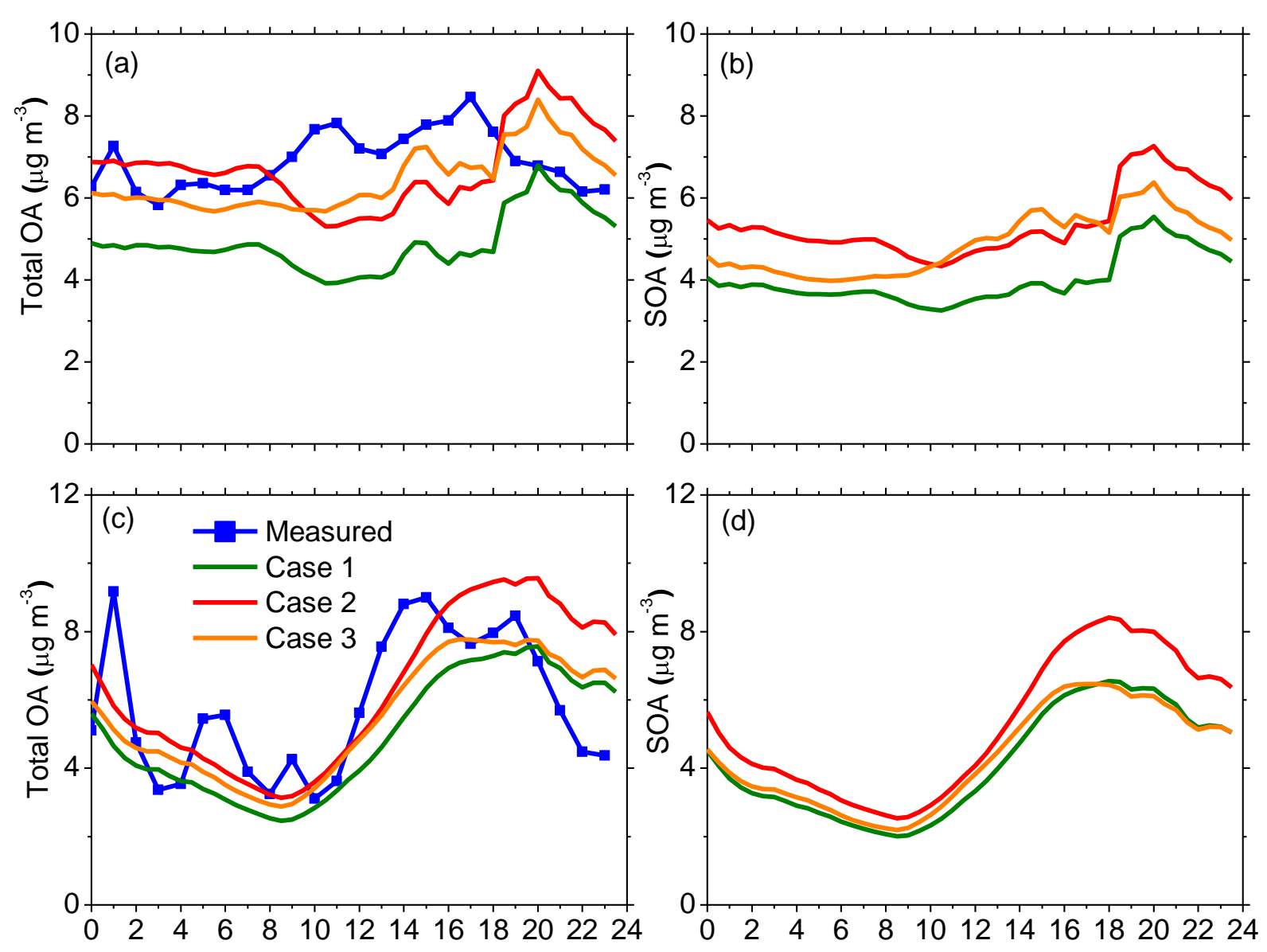

Figure S1: Average diurnal observed and simulated concentrations of (a) Total OA at T2 site (b) SOA at T2 site (c) Total OA at Altzomoni mountain site (d) SOA at Altzomoni mountain site. 
314

315

316

317

318

319

320

321

322

323

324

325

326

327

328

329

330

331

332

333

334

335

336

337

338

339

340

341

342

343

344

345

346

347

348

349

350

351

352

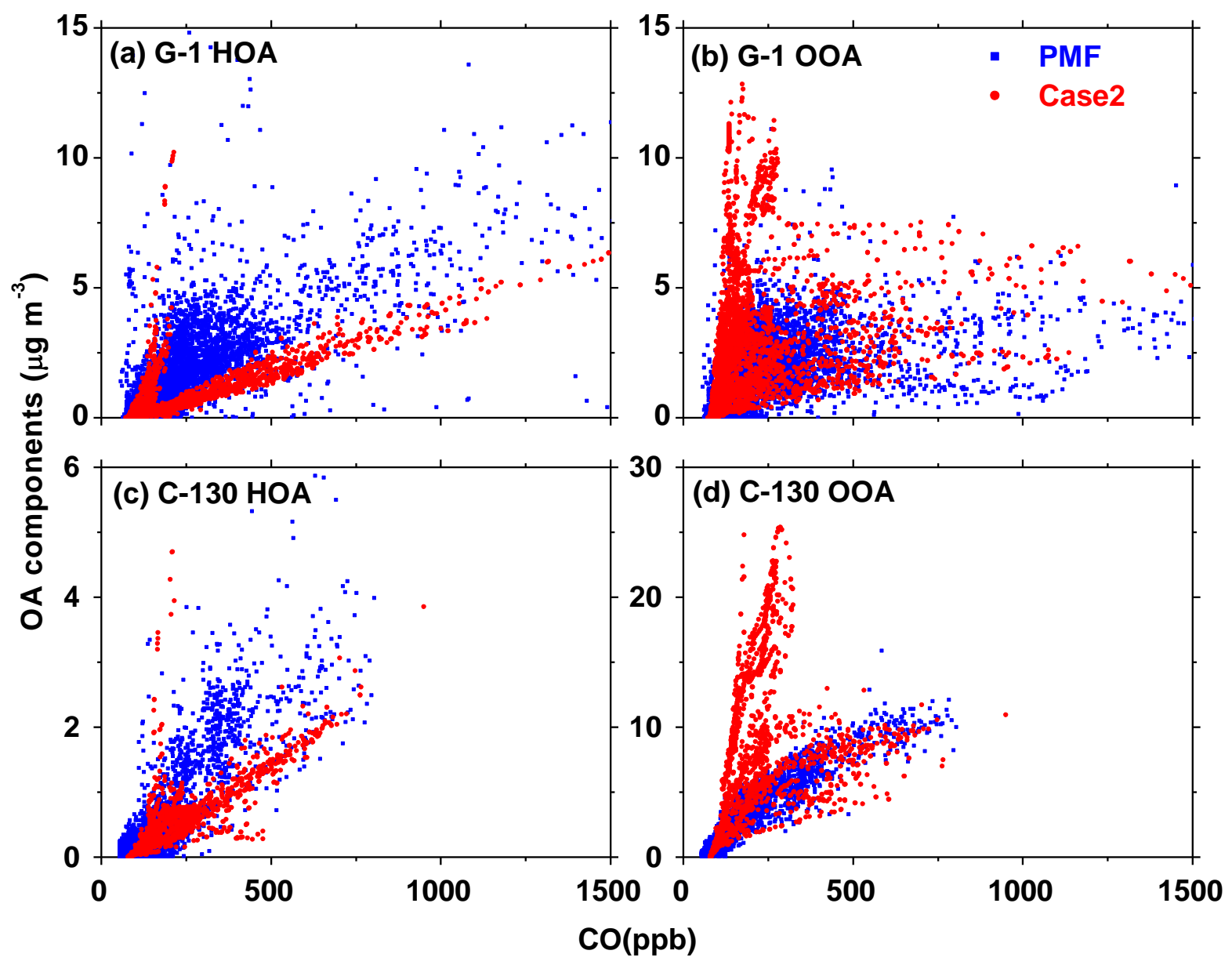

Figure S2: WRF-Chem (Case 2) predictions of OA components vs. CO mixing ratios (a) HOA for 8 G1 flights (b) OOA for 8 G-1 flights (c) HOA for 2 C-130 flights (d) OOA for 2 C130 flights 


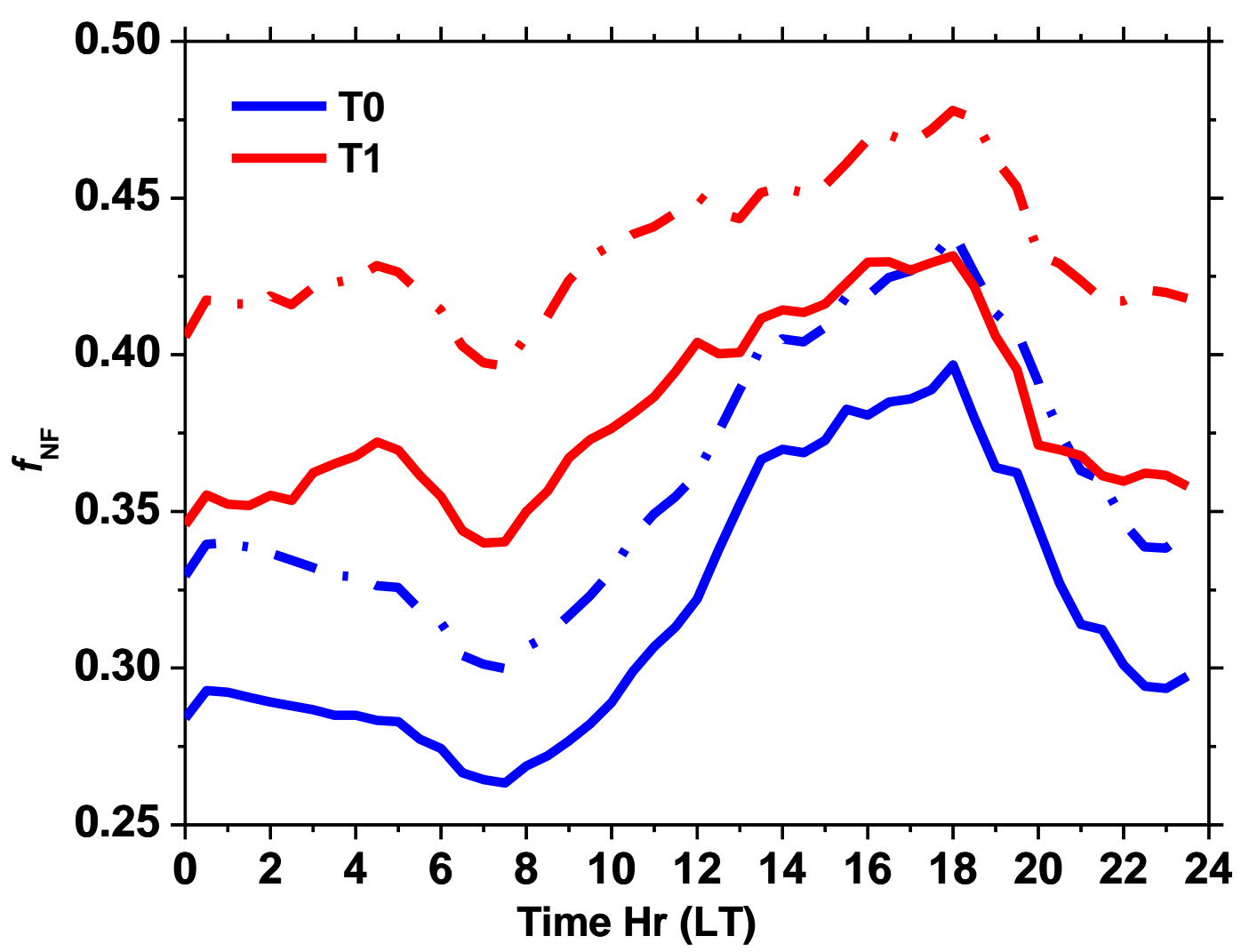

Figure S3: Average diurnal variation of non-fossil carbon fraction $\left(f_{\mathrm{NF}}\right)$ at the T0 and T1 sites in Mexico City region for March 6-30 2006. Solid lines represent Case 2 in this study, while dashed lines represent the same modeling Case (Case 2) with 5 times predicted biogenic B-V-SOA concentrations at T0 and T1 sites. Increasing biogenic SOA concentration by a factor of 5 increases predicted $f_{\mathrm{NF}}$ by 0.05 at both sites. 


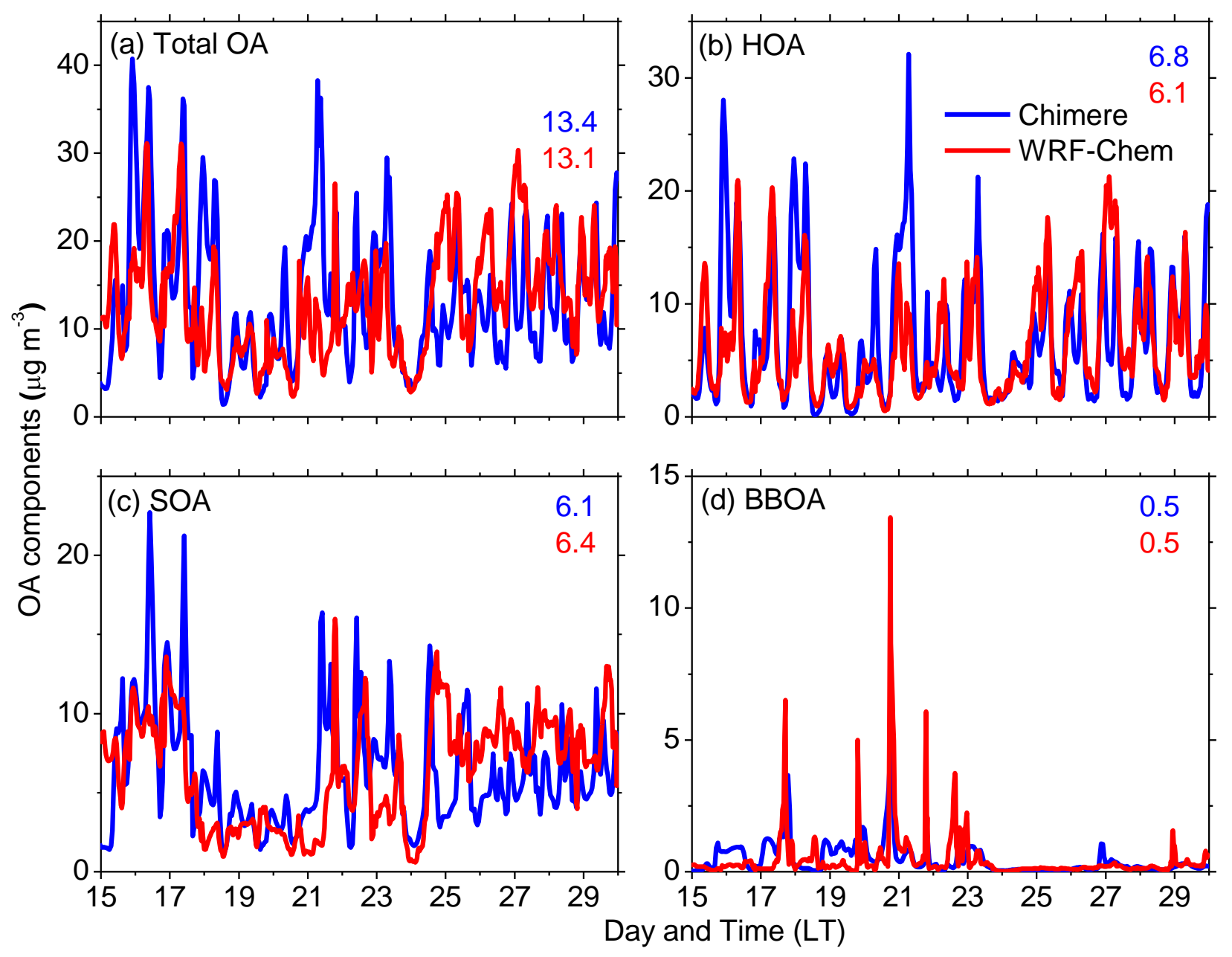

373 Figure S4: Comparing predictions of (a) total OA, (b) HOA, (c) SOA and (d) BBOA from

374 CHIMERE (using the ROB approach) vs. WRF-Chem model (Case 2) at the T0 site in Mexico

375 City. The mean predicted values from the two models are also indicated. 


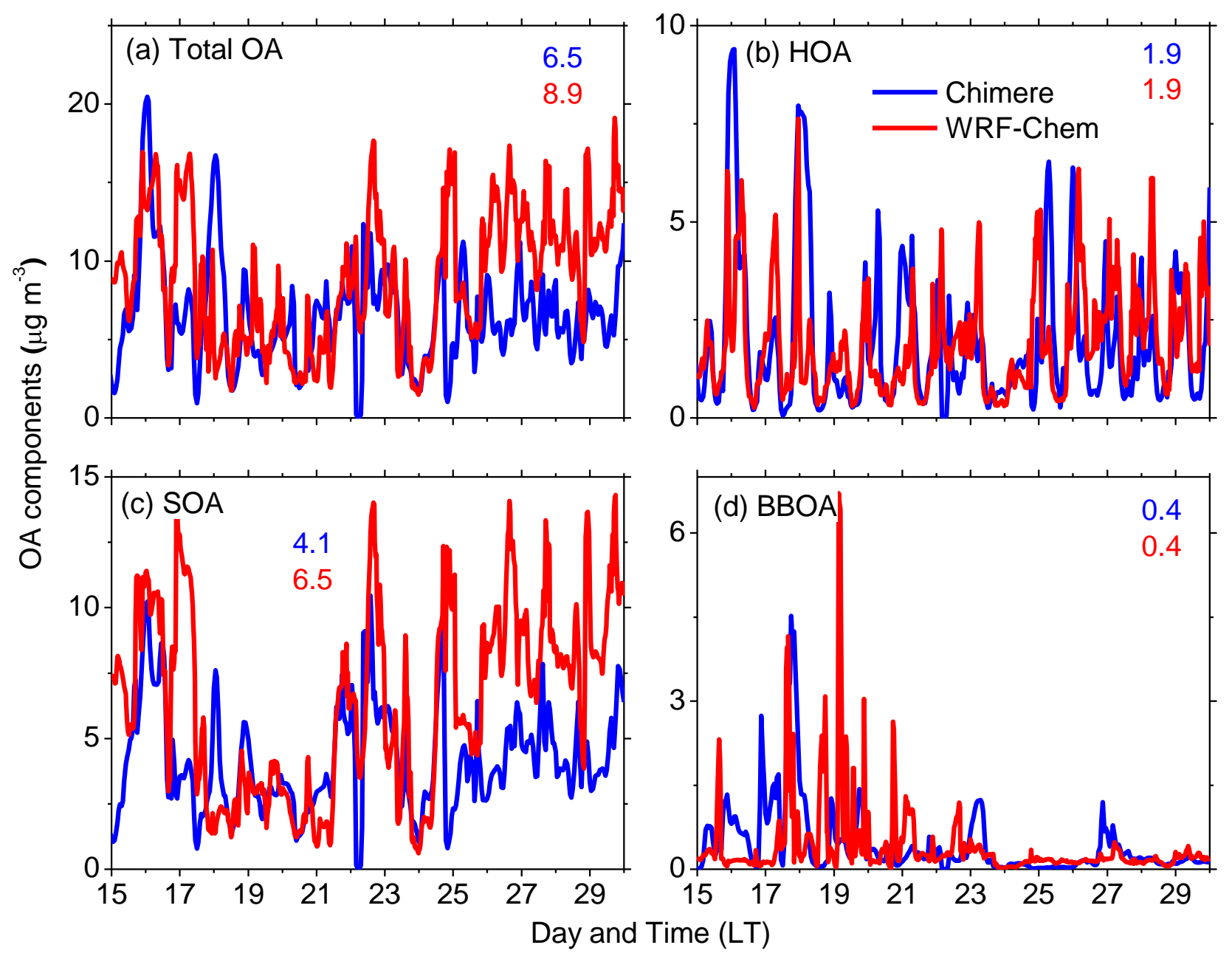

381 Figure S5: Comparing predictions of (a) total OA, (b) HOA, (c) SOA and (d) BBOA from

382 CHIMERE (using the ROB approach) vs. WRF-Chem model (Case 2) at the T1 site in Mexico

383 City. The mean predicted values from the two models are also indicated. 


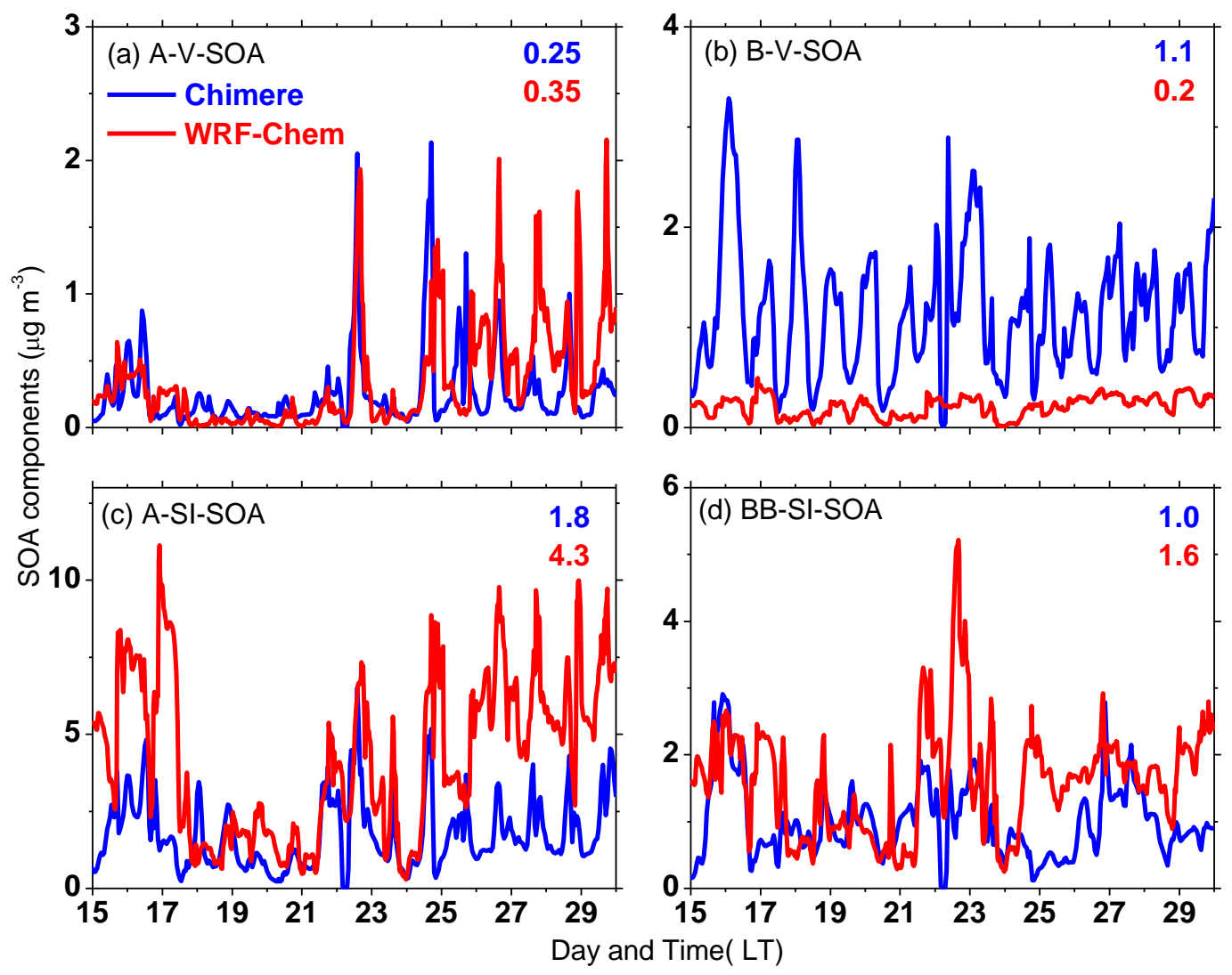

391 Figure S6: Comparing predictions of SOA components from CHIMERE (using the ROB

392 approach) vs. WRF-Chem model at the T1 site in Mexico City (a) traditional ant V-SOA (b)

393 biogenic V-SOA (c) anthropogenic SI-SOA (d) biomass burning SI-SOA. Temporally averaged 394 values are also indicated on each figure. 


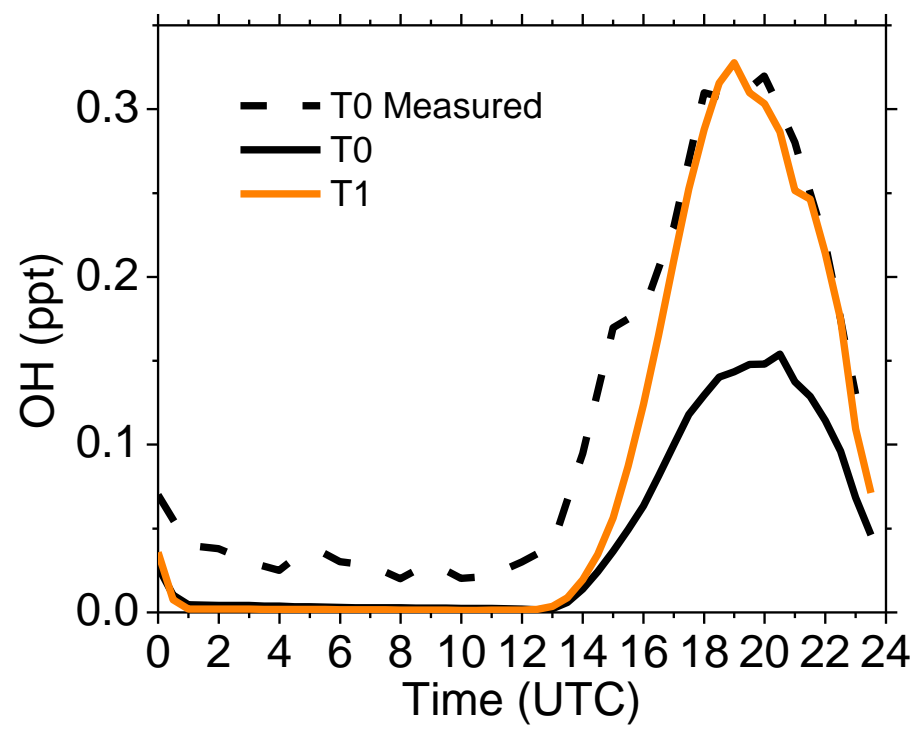

401

402 Figure S7: Comparison of measured vs. WRF-Chem predicted 24-day average diurnal variation 403 of $\mathrm{OH}$ concentration at T0 site in Mexico City. Predicted diurnal variation of $\mathrm{OH}$ at T1 site is 404 also included for comparison. 